\title{
Effect of liver transplantation in combined hepatocellular and cholangiocellular carcinoma: a case series
}

\author{
Di Wu, Zhong-Yang Shen", Ya-Min Zhang*, Jian Wang, Hong Zheng, Yong-Lin Deng and Cheng Pan
}

\begin{abstract}
Background: Liver transplantation is a treatment option for combined hepatocellular and cholangiocellular carcinoma (cHCC-CC) but its prognostic significance remains unclear. The present study aimed to evaluate the therapeutic effects of liver transplantation on CHCC-CC and analyze the clinicopathological factors affecting prognosis.

Methods: Retrospective analysis of the clinicopathological data of a case series of 21 patients with CHCC-CC who underwent orthotopic liver transplantation from April 2000 to April 2011 was performed. Cumulative survival rate and tumor-free survival rate were calculated using the Kaplan-Meier method followed by the log-rank test.

Results: The operative survival rate of the 21 patients was 100\%; the 30 day mortality was 4.8\% (1/21) and 90-day mortality was 9.5\% (2/21); 1-, 2-, 3-, and 5-year overall cumulative survival rates were 64\%, 47\%, 39\%, and 39\%, respectively; and the corresponding cumulative tumor-free survival rates were $64 \%, 37 \%, 30 \%$, and 30\%, respectively. Cumulative tumor diameter, lymph node metastasis, macroscopic portal vein tumor thrombus, and mixed states according to Allen typing were identified as the primary influencing factors of poor prognosis (all $P<0.05$ ).
\end{abstract}

Conclusion: Liver transplantation may be an effective therapeutic method for the treatment of CHCC-CC. Strict screening of potential liver transplantation candidates with CHCC-CC can help reduce the risks of tumor recurrence and metastasis.

Keywords: Combined hepatocellular and cholangiocellular carcinoma, Liver neoplasm, Cholangiocarcinoma, Liver transplantation, Prognosis, Recurrence, Neoplasm recurrence, Local

\section{Background}

Combined hepatocellular and cholangiocellular carcinoma (cHCC-CC) is an uncommon but discrete variant of primary liver cancer, with different biological behavior from hepatocellular carcinoma (HCC) and cholangiocellular carcinoma (CC). It accounts for $0.4-14 \%$ of all primary malignant liver tumors [1]. Histologically the tumor demonstrates features of both hepatocellular and cholangiocellular epithelial differentiation [2]. cHCC-CC is more common in males than in females [3]. The median survival of patients with non-surgical treatment is approximately four months; and the respective 1-, 3-, and 5 -year survival rates have been shown to be $26.5 \%$, $12.5 \%$, and $9.2 \%$, respectively [1]. The accompanying disease characteristics include hepatitis B virus/hepatitis C

\footnotetext{
*Correspondence: zhongyangshen@gmail.com; zhangyamin@medmail.com.cn Department of Hepatobiliary Surgery, Orient Organ Transplant Center, The
} First Center Hospital of Tianjin, Tianjin 300192, China virus infection, liver cirrhosis, vascular thrombosis, and hilar lymph node metastasis. Some of the features of cHCC-CC such as association with hepatitis virus and portal vein thrombosis are similar to HCC [4], whereas other features such as poor blood supply to the tumor and early onset of hilar and retroperitoneal lymph node metastasis are similar to $\mathrm{CC}$ [5]. The clinical features of cHCC-CC may be related to the dominant component in the tumor body. When bile duct-derived cancer cells are absolutely dominant in the tumor body, cHCC-CC clinically manifests to be more similar to CC.

Therapeutic methods for cHCC-CC include conservative treatment, liver resection (hepatectomy), and liver transplantation [3]. Other methods including local ablation (e.g., ethanol injection, microwave coagulation, and radiofrequency ablation [RFA]) and transcatheter arterial chemoembolization (TACE) have proved effective only in a small number of cases [6]. Local treatment methods 
such as TACE and percutaneous ethanol injection may have poor efficacy because of abundant interfibrillar substances and the poor blood supply found in cHCC-CC [7]. Liver resection can prolong the survival of a patient with cHCC-CC who has an early tumor stage and liver function that is tolerant to resection, and has achieved postoperative median survival times of 20 to 47 months [1].

Liver transplantation provides an option for the treatment of cHCC-CC in patients intolerant to liver resection [8]. The advantages of liver transplantation are better dissection of lymph nodes, elimination of background diseases of liver cancer, and no postoperative risk of liver dysfunction due to liver resection. Patients with cHCC-CC receiving liver transplantation have shown better survival than the same-stage patients with $\mathrm{cHCC}$ $\mathrm{CC}$ undergoing hepatectomy $[3,8]$. Similarly, liver transplant recipients with $\mathrm{HCC}$ have better survival rates than patients with cHCC-CC [9].

The clinical outcome of liver transplantation in patients with hepatocellular carcinoma (HCC) is well defined. But, there are fewer clinical reports available on liver transplantation in the treatment of $\mathrm{cHCC}-\mathrm{CC}$, and factors relevant to its prognosis remain unclear. The present study aimed to explore the clinical efficacy of liver transplantation in patients with cHCC-CC and evaluate the effects of different clinicopathological factors on prognosis of cHCC-CC. This information should add important data to that already available on the best treatment option for patients with cHCC-CC and whether liver transplant should be selected.

\section{Methods}

\section{Clinical data}

From April 2000 to April 2011, a cases series of 21 patients with cHCC-CC who underwent orthotopic liver transplantation (OLT) were selected from the First Center Hospital of Tianjin (Tianjin, China). This study was approved by the ethics committee of the First Center Hospital of Tianjin (E2014008L) and complied with the Declaration of Helsinki, and all participants provided written informed consent.

The cases included male patients whose diagnoses were pathologically confirmed as cHCC-CC with an age of onset of 35 to 65 years (mean age, 53 years). Twenty patients had hepatitis (fifteen with hepatitis B, four with hepatitis $\mathrm{C}$, and one with hepatitis $\mathrm{B}$ and $\mathrm{C}$ ) and one patient did not have hepatitis. According to the Child-Pugh classification of severity of liver disease, patients with cHCC-CC were classified as follows: sixteen patients with Grade A liver disease, three patients with Grade B liver disease, and two patients with Grade $\mathrm{C}$ liver disease. Prior to liver transplantation, 13 patients had not received preoperative adjuvant therapy. While eight patients had received preoperative adjuvant therapy including TACE and/or radiofrequency ablation (RFA, $\mathrm{n}=7$ ) and chemotherapy pump placement $(\mathrm{n}=1)$. The patients' preoperative serum $\alpha$-fetoprotein (AFP) level $(\mathrm{n}=13)$ was $>20 \mathrm{ng} / \mathrm{mL}$ and preoperative carbohydrate antigen 19-9 (CA 19-9) level $(\mathrm{n}=12)$ was $\geq 37 \mathrm{U} / \mathrm{mL}$.

Intraoperatively resected liver tissues were used for routine histopathological examinations. In the 21 cases 18 patients had cirrhosis while the remaining three patients had no cirrhosis. Five patients had single tumors, eight patients had 2 to 3 tumors, and eight patients had $\geq 4$ tumors. Twelve patients had tumor lesions in the right lobe, while the remaining nine patients had tumor lesions in both the right and left lobes of the liver. Cumulative tumor diameter (the maximal diameter of single tumors or the sum of tumor diameters for multi-tumors) was $\leq 5 \mathrm{~cm}$ in four patients, 5 to $10 \mathrm{~cm}$ in seven patients, and $>10 \mathrm{~cm}$ in ten patients. Patients also had accompanying diseases such as hilar lymph node metastasis $(n=5)$, macroscopic portal vein tumor thrombus $(n=8)$, and microvascular thrombosis $(n=14)$. The component in HCC was moderately or well differentiated in sixteen patients and poorly differentiated in five patients. The component in $\mathrm{CC}$ was moderately or well differentiated in twelve patients and poorly differentiated in nine patients. According to the typing method of Allen et al., [10] there were twelve patients in the separation state, three patients in the collision state, and six patients in the mixed state.

All 21 patients underwent conventional non-bypass OLT from a cadaver donor of the same blood type. Postoperatively, the patients received a standard triple immunosuppressive therapy with hormone + tacrolimus $\left(\right.$ FK506) + mycophenolate mofetil $\left(\right.$ CellCept $\left.^{\circ}\right)$ for three months. Thereafter, tacrolimus (FK506) was administered individually to maintain blood trough concentration at 3 to $6 \mathrm{ng} / \mathrm{mL}$.

\section{Follow-up}

All patients were either hospitalized or visited as outpatients for follow-up. There were no patients lost to follow up. The patients were re-examined postoperatively by abdominal ultrasound, chest $\mathrm{x}$-ray, and blood tests (serum AFP and CA 19-9 measurements) monthly, and at six months and quarterly thereafter. The patients underwent a chest and abdominal computed tomography scan, and bone scan for diagnosis of tumor recurrence. The time and cause of death were followed up.

\section{Statistical analysis}

Data were statistically analyzed using SPSS, version 15.0 (SPSS Inc., Chicago, IL, USA). Cumulative survival rate and tumor-free survival rate were calculated using the Kaplan-Meier method, followed by the log-rank test for univariate analysis. A $P$-value of less than 0.05 was considered statistically significant. 


\section{Results}

\section{Follow-up results}

As of April 2013, 14 recipients of liver transplants survived over a year. In the 21 case series, the operative survival rate of the patients was $100 \%$, the 30 day mortality was $4.8 \%(1 / 21)$ and 90 -day mortality was $9.5 \%(2 / 21)$. One patient died due to an aneurysm rupture and bleeding during the first postoperative month. Another two patients died due to lung infection two and four months postoperatively. 8 of the 21 patients recurred or died of procedure related events within 6 months of transplant. Among these 8 patients, 3 had lymph nodes metastases.

The cumulative 1-, 2-, 3-, and 5-year overall survival rates of the 21 patients with cHCC-CC were $64 \%, 47 \%$, $39 \%$, and $39 \%$, respectively (Figure 1 ).

The cumulative 1-, 2-, 3, and 5-year tumor-free survival rates of the patients with cHCC-CC were $64 \%$, $37 \%, 30 \%$, and $30 \%$, respectively (Figure 2 ).

The median survival time of the 21 patients with cHCC-CC was 23 months.

\section{Univariate analysis}

The univariate analysis of relevant clinicopathological factors showed that the influencing factors of poor prognosis included cumulative tumor diameter, lymph node metastasis, macroscopic portal vein tumor thrombus, and mixed states according to Allen type (all $P<0.05$ ) (Table 1).

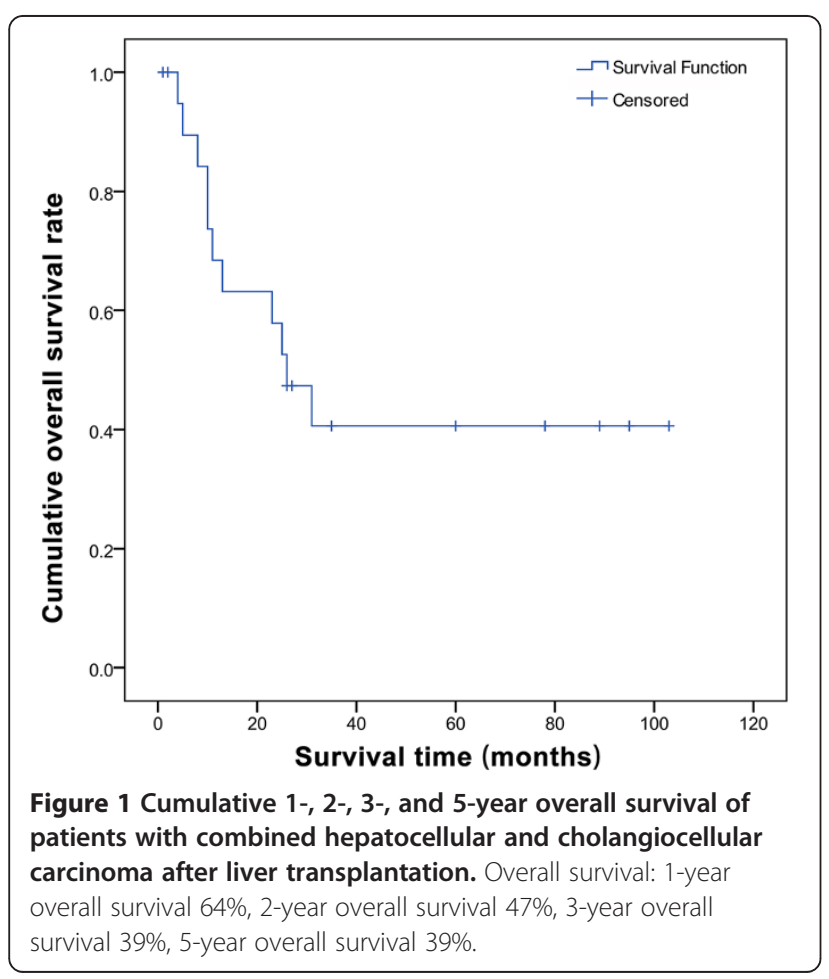

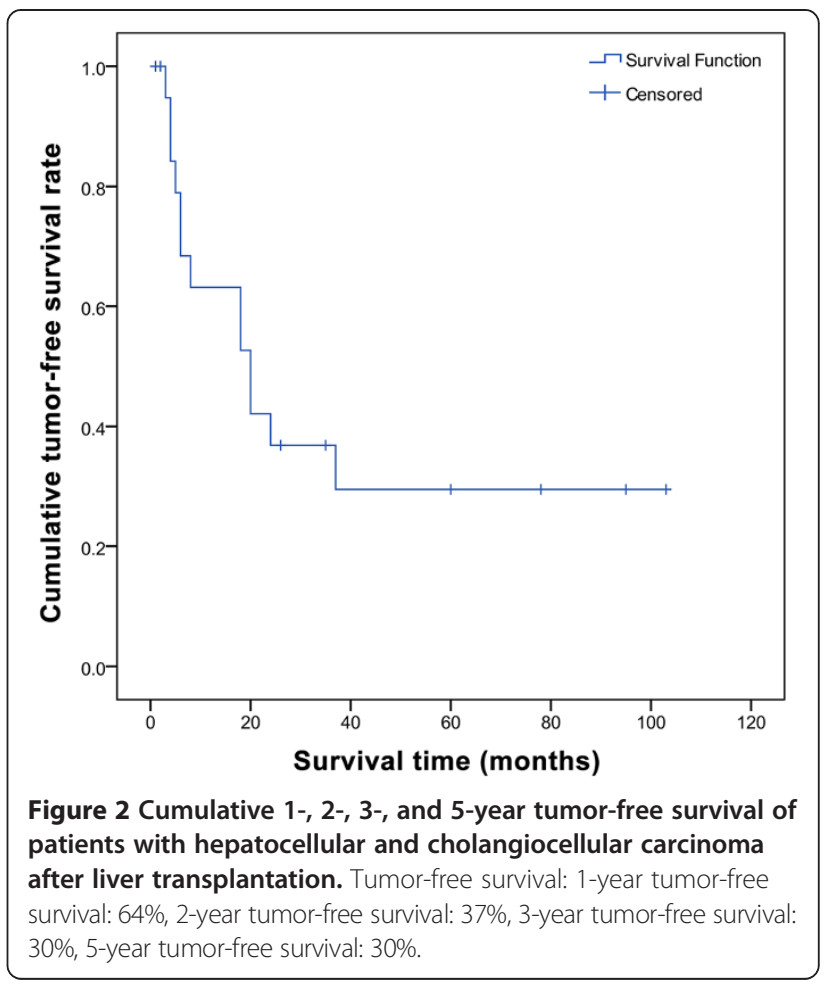

Baseline characteristics of patients whose tumor recurred within 1 or 2 years

Of the 21 patients, 7 showed recurrence of tumors during the first year $(33.3 \%)$ and 11 within 2 years $(52.4 \%)$ (Table 2). The patients that had tumor recurrence within 1 year showed mean tumor sizes of $11.86 \pm 2.90 \mathrm{~cm}$ in diameter and within 2 years $11.00 \pm 4.13 \mathrm{~cm}$ in diameter. Patients whose tumor recurred within 1 or 2 years had similar presence of lymph node metastases, $2 / 7$ (28.6\%) and $3 / 11$ (27.3\%), respectively. Of the patients with tumor recurrence within 2 years, 9 (81.8\%) had cirrhosis (Table 2).

\section{Discussion}

Although relatively rare, cHCC-CC accounts for 0.4$14 \%$ of primary liver cancers [1]. There is some evidence that liver transplantation may be the best available treatment for improving survival rates [3,9]. The aim of this investigation was to retrospectively assess the outcomes of patients with cHCC-CC undergoing liver transplant and to investigate the factors that might be involved in the prognosis of the patients. We found that the fiveyear overall survival rate was $39 \%$. Univariate analysis suggests that prognosis is related to the clinicopathological factors of cumulative tumor diameter, lymph node metastasis, macroscopic portal vein tumor thrombus and mixed states according to Allen type.

In the present study, the cHCC-CC disease manifestations of the 21 male patients were as follows: combined 
Table 1 Effects of different clinicopathological factors on the survival of patients with combined hepatocellular and cholangiocellular carcinoma after liver transplantation

\begin{tabular}{|c|c|c|c|}
\hline Prognostic factors & $\begin{array}{l}\text { Cases } \\
(\%)\end{array}$ & $\begin{array}{l}\text { Mean survival } \\
\text { time (month) }\end{array}$ & $P$-value \\
\hline \multicolumn{4}{|l|}{ Age } \\
\hline$<50$-year & $7(33 \%)$ & $50.8 \pm 18.1$ & 0.899 \\
\hline$\geq 50$-year & $14(67 \%)$ & $45.0 \pm 11.8$ & \\
\hline \multicolumn{4}{|l|}{ Preoperative treatment } \\
\hline None & $13(62 \%)$ & $46.7 \pm 12.3$ & 0.769 \\
\hline TACE, RFA, or chemotherapy & $8(38 \%)$ & $49.0 \pm 14.1$ & \\
\hline \multicolumn{4}{|l|}{ Preoperative AFP } \\
\hline$<20 \mathrm{ng} / \mathrm{mL}$ & $8(38 \%)$ & $44.0 \pm 17.2$ & 0.898 \\
\hline$\geq 20 \mathrm{ng} / \mathrm{mL}$ & $13(62 \%)$ & $37.1 \pm 9.5$ & \\
\hline \multicolumn{4}{|l|}{ Preoperative CA19-9 } \\
\hline$<37 \mathrm{U} / \mathrm{mL}$ & $9(43 \%)$ & $53.6 \pm 15.8$ & 0.268 \\
\hline$\geq 37 \mathrm{U} / \mathrm{mL}$ & $12(57 \%)$ & $48.8 \pm 8.9$ & \\
\hline \multicolumn{4}{|l|}{ Child-Pugh Grading } \\
\hline Grade A & $16(76 \%)$ & $47.3 \pm 13.1$ & 0.347 \\
\hline Grade B & $3(14 \%)$ & $39.1 \pm 9.1$ & \\
\hline Grade C & $2(10 \%)$ & $53.6 \pm 12.0$ & \\
\hline \multicolumn{4}{|l|}{ Cirrhosis* $^{*}$} \\
\hline No & $3(14 \%)$ & $9.0 \pm 1.0$ & 0.031 \\
\hline Yes & $18(86 \%)$ & $52.8 \pm 11.1$ & \\
\hline \multicolumn{4}{|l|}{ Tumor distribution } \\
\hline Right lobe & $12(57 \%)$ & $53.5 \pm 12.9$ & 0.265 \\
\hline Double lobes & $9(43 \%)$ & $41.3 \pm 10.2$ & \\
\hline \multicolumn{4}{|l|}{ Cumulative tumor diameter* } \\
\hline$\leq 5 \mathrm{~cm}$ & $4(19 \%)$ & $83.5 \pm 16.9$ & 0.047 \\
\hline $5-10 \mathrm{~cm}$ & 7 (33\%) & $32.8 \pm 10.1$ & \\
\hline$>10 \mathrm{~cm}$ & $10(48 \%)$ & $17.7 \pm 4.0$ & \\
\hline \multicolumn{4}{|l|}{ Tumor quantity } \\
\hline Singular & $5(24 \%)$ & $37.3 \pm 19.2$ & 0.084 \\
\hline $2-3$ & $8(38 \%)$ & $50.3 \pm 14.8$ & \\
\hline$\geq 4$ & $8(38 \%)$ & $34.3 \pm 13.0$ & \\
\hline \multicolumn{4}{|l|}{ Lymph node metastasis* } \\
\hline Yes & $5(24 \%)$ & $14.0 \pm 6.1$ & 0.039 \\
\hline No & $16(76 \%)$ & $54.7 \pm 11.7$ & \\
\hline \multicolumn{4}{|l|}{ HCC differentiation } \\
\hline $\begin{array}{l}\text { Intermediate to well } \\
\text { differentiated }\end{array}$ & $16(76 \%)$ & $54.3 \pm 15.2$ & 0.074 \\
\hline Poorly differentiated & $5(24 \%)$ & $45.6 \pm 12.1$ & \\
\hline \multicolumn{4}{|l|}{ CC differentiation } \\
\hline $\begin{array}{l}\text { Intermediate to well } \\
\text { differentiated }\end{array}$ & $12(57 \%)$ & $56.7 \pm 9.3$ & 0.083 \\
\hline Poorly differentiated & $9(43 \%)$ & $41.0 \pm 13.8$ & \\
\hline
\end{tabular}

Table 1 Effects of different clinicopathological factors on the survival of patients with combined hepatocellular and cholangiocellular carcinoma after liver transplantation (Continued)

\begin{tabular}{llll}
\hline $\begin{array}{l}\text { Macroscopic thrombosis* } \\
\text { Yes }\end{array}$ & $8(38 \%)$ & $21.0 \pm 5.1$ & 0.028 \\
$\quad$ No & $13(62 \%)$ & $57.9 \pm 13.1$ & \\
Microvascular thrombosis & & & \\
$\quad$ Yes & $14(67 \%)$ & $42.5 \pm 12.5$ & 0.226 \\
No & $7(33 \%)$ & $58.8 \pm 14.9$ & \\
Allen typing* & & & \\
$\quad$ Separation/collision & $15(71 \%)$ & $47.9 \pm 9.9$ & 0.037 \\
$\quad$ Mixed & $6(29 \%)$ & $21.3 \pm 14.2$ & \\
\hline
\end{tabular}

Note: AFP = alpha-fetoprotein; CA19-9 = carbohydrate antigen 19-9; $\mathrm{CC}=$ cholangiocellular carcinoma; $\mathrm{HCC}=$ hepatocellular carcinoma; $\mathrm{RFA}=$ radio frequency ablation; $\mathrm{TACE}=$ transcatheter arterial chemoembolization. * by the log-rank test, $P<0.05$.

hepatitis accounted for 95\% (20/21), cirrhosis accounted for $86 \%(18 / 21)$, vascular invasion accounted for $67 \%$ (14/21), and lymph node metastasis accounted for $24 \%$ $(5 / 21)$. The present study results are consistent with the data previously reported in the literature $[6,11,12]$. Kassahun and Hauss [1] comprehensively analyzed 424 cases of cHCC-CC in eighteen reports and indicated that hepatitis virus infection plays an important role in the pathogenesis of $\mathrm{CHCC}-\mathrm{CC}$. However, any differences in the mechanisms underlying the pathogenesis of HCC and $\mathrm{CHCC}-\mathrm{CC}$ remain unclear.

In the present study, postoperative cumulative 1-, 2-, 3 -, and 5-year survival rates of patients with cHCC-CC treated by liver transplantation were $64 \%, 47 \%, 39 \%$, and $39 \%$, respectively; and the corresponding cumulative tumor-free survival rates were $64 \%, 37 \%, 30 \%$, and $30 \%$. The overall survival rate of patients who underwent surgical OLT was better than the rates for non-surgical treatment as reported previously in the literature [6]. And the five-year overall survival was similar to previous studies that have evaluated this measure although lower than recent reports of $41 \%$ [3], 50\% [13] and 60\% [14] it was better than another at $16 \%$ [15]. These values are generally from small populations of patients because of the rarity of this disease so the values may reflect different patient pathological factors.

Tumor size and number, vascular invasion, and lymph node metastasis are important prognostic factors of liver transplantation in HCC $[16,17]$. In the present study the results of the univariate analysis showed that the cumulative tumor diameter, macrovascular invasion, and lymph node metastasis significantly affected the postoperative survival of patients with cHCC-CC (all $P<0.05$ ). Preoperative diagnosis of lymph node metastasis is difficult due to a lack of specificity in imaging studies. This 
Table 2 Baseline characteristics of patients with combined hepatocellular and cholangiocellular carcinoma after liver transplantation that had tumor recurrence within 1 or 2 years

\begin{tabular}{|c|c|c|c|c|c|c|c|c|c|}
\hline Patients (n) & Age (years) & $\begin{array}{l}\text { Free- tumor } \\
\text { survival time } \\
\text { (months) }\end{array}$ & $\begin{array}{l}\text { Survival time } \\
\text { (months) }\end{array}$ & $\begin{array}{l}\text { Cumulative tumor } \\
\text { diameter }(\mathrm{cm})\end{array}$ & $\begin{array}{l}\text { Tumor } \\
\text { quantity }\end{array}$ & $\begin{array}{l}\text { Lymph node } \\
\text { metastasis }\end{array}$ & $\begin{array}{l}\text { Macroscopic } \\
\text { thrombosis }\end{array}$ & $\begin{array}{l}\text { Microvascular } \\
\text { thrombosis }\end{array}$ & Cirrhosis \\
\hline \multicolumn{10}{|c|}{$\begin{array}{l}\text { Recurred within } \\
1 \text { year }\end{array}$} \\
\hline 2 & 61 & 5 & 10 & 14 & 3 & No & No & Yes & Yes \\
\hline 4 & 54 & 4 & 10 & 8 & 1 & No & No & Yes & No \\
\hline 5 & 59 & 8 & 13 & 12 & 5 & Yes & No & Yes & Yes \\
\hline 7 & 43 & 6 & 11 & 7 & 1 & No & No & No & Yes \\
\hline 8 & 35 & 3 & 5 & 15 & 6 & No & Yes & Yes & Yes \\
\hline 10 & 40 & 4 & 4 & 13 & 5 & Yes & Yes & Yes & Yes \\
\hline 20 & 55 & 6 & 8 & 14 & 2 & No & No & Yes & No \\
\hline \multicolumn{10}{|c|}{$\begin{array}{l}\text { Recurred within } \\
2 \text { year }\end{array}$} \\
\hline 9 & 53 & 18 & 25 & 4 & 1 & Yes & No & Yes & Yes \\
\hline 13 & 49 & 20 & 27 & 10 & 6 & No & No & Yes & Yes \\
\hline 14 & 59 & 18 & 23 & 6 & 2 & No & Yes & Yes & Yes \\
\hline 17 & 58 & 20 & 26 & 18 & 2 & No & Yes & No & Yes \\
\hline
\end{tabular}

is because lymphadenopathy may also be caused by reactive hyperplasia of lymph nodes. Thus, it is necessary to perform preoperative or intraoperative liver biopsy in suspected cases. For instance, in the present study the mixed states according to Allen typing posed significantly different influences on the prognosis from other types. These data suggest that mixed-state tumors may be more invasive than the other two types of tumor. The present study results also found that $9(81.8 \%)$ of the patients with recurrence within 2 years, had cirrhosis, this is perhaps associated with tumor development. Due to a lack of clinical cases, the above mechanism needs to be explored in future studies.

Three patients who died early post operatively had positive lymph nodes. One patient with lymph node metastasis died within 13 months and another patient with lymph nodes metastasis died within 25 months. 8 of the 21 patients had disease recurrence or died of procedure related events within 6 months of transplant. Among these 8 patients, 3 patients had lymph node metastases. This suggested that the effect of lymph node metastasis was very important. Panjala et al. reported that the 5year survival rate after liver transplantation was only $16 \%$ in 12 patients with $\mathrm{cHCC}-\mathrm{CC}$ without perineural or adjacent lymph node metastasis [15]. Because patients with lymph node metastasis had a poorer survival rate, we recommend freezing a section of suspicious lymph nodes at the time of surgical exploration or diagnostic laparoscopy prior to performing a transplant and the information this provides should alter the decision of whether to transplant or not. Careful selection of patients without lymph node metastasis may help to improve survival rates and reduce tumor recurrence rates in patients with $\mathrm{cHCC}-\mathrm{CC}$ after liver transplantation.

A significant limitation of this study is the relatively few cases of $\mathrm{cHCC}-\mathrm{CC}$ that were encountered and suitable for liver transplant, necessarily resulting in a small sample size. This may introduce some bias in the analysis of factors related to patient prognosis, giving some unexpected results such as longer term survival of the patients with cirrhosis of the liver.

\section{Conclusion}

In conclusion, liver transplantation may be an effective clinical therapy with prolonged survival for a subgroup of patients with $\mathrm{cHCC}-\mathrm{CC}$. However, recurrence within the first two years is common, suggesting the need to develop selection criteria for OLT in this pathologic entity. The current study considers the effects of cumulative tumor diameter, vascular invasion, lymph node metastasis, and the type of cHCC-CC. Rigorous preoperative assessment of these criteria could enhance patient selection for OLT associated with $\mathrm{cHCC}-\mathrm{CC}$, thereby leading to reduced postoperative tumor recurrence and improved survival.

\section{Abbreviations}

CHCC-CC: Combined hepatocellular and cholangiocellular carcinoma;

OLT: Orthotopic liver transplantation; AFP: Alpha-fetoprotein; CA19-

9: Carbohydrate antigen 19-9; CC: Cholangiocellular carcinoma;

HCC: Hepatocellular carcinoma; RFA: Radio frequency ablation;

TACE: Transcatheter arterial chemoembolization.

\section{Competing interests}

The authors declare that they have no competing interests. 


\section{Authors' contributions}

DW carried out the studies on liver transplantation for CHCC-CC, participated in analysis of the clinical and pathological characteristics of CHCC-CC after liver transplantation and drafted the manuscript. YMZ carried out the surgical therapy of HCC, participated in the resection and liver transplantation. JW conceived of the study, and participated in its design and coordination and helped to draft the manuscript. $\mathrm{HZ}$ participated in the liver transplantation operation. CP participated in the liver transplantation. ZYS carried out the study of liver transplantation, participated in the criteria for liver transplantation. All authors read and approved the final manuscript.

\section{Authors' information}

Di Wu and Jian Wang are co-first authors.

\section{Acknowledgements}

This work was supported by National High Technology Research and Development Program (863 Program) of China (Grant No.2012AA021001).

Received: 16 April 2014 Accepted: 25 March 2015

Published online: 08 April 2015

\section{References}

1. Kassahun WT, Hauss J. Management of combined hepatocellular and cholangiocarcinoma. Int J Clin Pract. 2008;62:1271-8.

2. Jarnagin WR, Weber S, Tickoo SK, Koea JB, Obiekwe S, Fong Y, et al. Combined hepatocellular and cholangiocarcinoma: demographic, clinical, and prognostic factors. Cancer. 2002;94:2040-6.

3. Garancini M, Goffredo P, Pagni F, Romano F, Roman S, Sosa JA, et al. Combined hepatocellular-cholangiocarcinoma: a population-level analysis of an uncommon primary liver tumor. Liver Transpl. 2014;20:952-9.

4. Chantajitr S, Wilasrusmee C, Lertsitichai P, Phromsopha N. Combined hepatocellular and cholangiocarcinoma: clinical features and prognostic study in a Thai population. J Hepatobiliary Pancreat Surg. 2006;13:537-42.

5. Liver Cancer Study Group of Japan. Primary liver cancer in Japan. Clinicopathologic features and results of surgical treatment. Ann Surg. 1990;211:277-87

6. Ikai I, Arii S, Ichida T, Okita K, Omata M, Kojiro M, et al. Report of the 16th follow-up survey of primary liver cancer. Hepatol Res. 2005;32:163-72.

7. Dick EA, Taylor-Robinson SD, Thomas HC, Gedroyc WMW. Ablative therapy for liver tumours. Gut. 2002;50:733-9.

8. Chan AC, Lo CM, Ng IO, Fan ST. Liver transplantation for combined hepatocellular cholangiocarcinoma. Asian J Surg. 2007;30:143-6.

9. Chen $\mathrm{HL}$, Zheng $\mathrm{H}$, Wang ZL, Zhu ZJ, Deng YL, Pan C, et al. Liver transplantation in 14 patients with combined hepatocellular and cholangiocellular carcinoma. Chin J Clin Oncol. 2009;36:486-9.

10. Allen RA, Lisa JR. Combined Liver Cell and Bile Duct Carcinoma. Am J Pathol. 1949;25:647-55

11. Koh KC, Lee H, Choi MS, Lee JH, Paik SW, Yoo BC, et al. Clinicopathologic features and prognosis of combined hepatocellular cholangiocarcinoma. Am J Surg. 2005;189:120-5

12. Liu CL, Fan ST, Lo CM, Ng IO, Lam CM, Poon RT, et al. Hepatic resection for combined hepatocellular and cholangiocarcinoma. Arch Surg. 2003;138:86-90

13. Song S, Moon HH, Lee S, Kim TS, Shin M, Kim JM, et al. Comparison between resection and transplantation in combined hepatocellular and cholangiocarcinoma. Transplant Proc. 2013:45:3041-6.

14. Park YH, Hwang S, Ahn CS, Kim KH, Moon DB, Ha TY, et al. Long-term outcome of liver transplantation for combined hepatocellular carcinoma and cholangiocarcinoma. Transplant Proc. 2013;45:3038-40.

15. Panjala C, Senecal DL, Bridges MD, Kim GP, Nakhleh RE, Nguyen JH, et al. The diagnostic conundrum and liver transplantation outcome for combined hepatocellular-cholangiocarcinoma. Am J Transplant. 2010;10:1263-7.

16. Mazzaferro V, Regalia E, Doci R, Andreola S, Pulvirenti A, Bozzetti F, et al. Liver transplantation for the treatment of small hepatocellular carcinomas in patients with cirrhosis. N Engl J Med. 1996:334:693-9.

17. Lee WS, Lee KW, Heo JS, Kim SJ, Choi SH, Kim Yl, et al. Comparison of combined hepatocellular and cholangiocarcinoma with hepatocellular carcinoma and intrahepatic cholangiocarcinoma. Surg Today. 2006;36:892-7.

\section{Submit your next manuscript to BioMed Central and take full advantage of:}

- Convenient online submission

- Thorough peer review

- No space constraints or color figure charges

- Immediate publication on acceptance

- Inclusion in PubMed, CAS, Scopus and Google Scholar

- Research which is freely available for redistribution

Submit your manuscript at www.biomedcentral.com/submit 